\title{
Glial cells in the mouse enteric nervous system can undergo neurogenesis in response to injury
}

\author{
Catia Laranjeira, ${ }^{1}$ Katarina Sandgren, ${ }^{1}$ Nicoletta Kessaris, ${ }^{2}$ William Richardson, ${ }^{2}$ \\ Alexandre Potocnik, ${ }^{3}$ Pieter Vanden Berghe, ${ }^{4}$ and Vassilis Pachnis ${ }^{1}$
}

\begin{abstract}
1Division of Molecular Neurobiology, Medical Research Council (MRC) National Institute for Medical Research (NIMR), London, United Kingdom. 2Wolfson Institute for Biomedical Research and Department of Cell and Developmental Biology, University College London, London, United Kingdom. ${ }^{3}$ Division of Molecular Immunology, MRC National Institute for Medical Research, United Kingdom. ${ }^{4}$ Laboratory of Enteric Neuroscience (LENS), TARGID, KULeuven, Leuven, Belgium.
\end{abstract}

\begin{abstract}
The enteric nervous system (ENS) in mammals forms from neural crest cells during embryogenesis and early postnatal life. Nevertheless, multipotent progenitors of the ENS can be identified in the adult intestine using clonal cultures and in vivo transplantation assays. The identity of these neurogenic precursors in the adult gut and their relationship to the embryonic progenitors of the ENS are currently unknown. Using genetic fate mapping, we here demonstrate that mouse neural crest cells marked by SRY box-containing gene 10 (Sox10) generate the neuronal and glial lineages of enteric ganglia. Most neurons originated from progenitors residing in the gut during mid-gestation. Afterward, enteric neurogenesis was reduced, and it ceased between 1 and 3 months of postnatal life. Sox10-expressing cells present in the myenteric plexus of adult mice expressed glial markers, and we found no evidence that these cells participated in neurogenesis under steady-state conditions. However, they retained neurogenic potential, as they were capable of generating neurons with characteristics of enteric neurons in culture. Furthermore, enteric glia gave rise to neurons in vivo in response to chemical injury to the enteric ganglia. Our results indicate that despite the absence of constitutive neurogenesis in the adult gut, enteric glia maintain limited neurogenic potential, which can be activated by tissue dissociation or injury.
\end{abstract}

\section{Introduction}

Establishment of functional circuits in the nervous system depends on the precise spatiotemporal generation of interconnected neuronal subtypes. In the CNS, postmitotic neurons are generated from neural stem cells (NSCs), which have the capacity to self-renew and differentiate into neuronal, astrocytic, and oligodendrocytic lineages (1). Over the last two decades, it has become clear that neurogenesis persists in the adult mammalian brain with astrocyte-like NSCs found in the subventricular zone of the lateral ventricles and the subgranular zone of the dentate gyrus (2). Although embryonic and adult NSCs share morphological and molecular properties, their exact relationship remains unclear. In vertebrates, the peripheral nervous system (PNS) is derived from neural crest stem cells (NCSCs), which migrate throughout the embryo and generate the majority of peripheral neurons and glia (3). Interestingly, the carotid body, an oxygen-sensing organ of the sympathoadrenal lineage, remains a neurogenic center throughout adulthood, with glia-like sustentacular cells giving rise to new neuron-like glomus cells in response to hypoxemia (4). Despite these studies, the presence and identity of stem cells in the ganglia of the PNS, their relationship to embryonic NCSCs, and their neurogenic potential in adult animals remain unknown.

The enteric nervous system (ENS), which regulates the peristaltic and secretory activity of the gut wall (5), is derived from enteric NCSCs (eNCSCs), which emerge during embryogenesis from the hindbrain and following stereotypical migratory patterns colonize the entire gastrointestinal tract (6). The transcription factor Sox10

Conflict of interest: The authors have declared that no conflict of interest exists. Citation for this article: J Clin Invest. 2011;121(9):3412-3424. doi:10.1172/JCI58200. is one of the earliest neural crest cell markers of ENS progenitors $(7,8)$. Sox10 is first detected in NCSCs that delaminate from the neural tube and migrate to invade the gut (9). Upon deletion of Sox 10 , enteric ganglia fail to form, demonstrating a critical role of this transcriptional regulator in ENS development (10). In vitro studies have suggested that Sox10-expressing undifferentiated progenitors in embryonic gut generate both enteric neurons (Sox10-) and glia $\left(\right.$ Sox $\left.10^{+}\right)$, but the neurogenic potential of these cells in vivo and its temporal regulation during gut organogenesis are currently unclear.

In rodents, enteric neurogenesis is restricted to embryonic stages and early postnatal life $(11,12)$. Nevertheless, self-renewing multipotent progenitors have been identified in cultures of post-neurogenic adult intestine $(13,14)$, while a recent report has provided evidence for enteric neurogenesis in adult animals in response to 5-hydroxytryptamine $4\left(5-\mathrm{HT}_{4}\right)$ receptor activation (12). In addition, it has been suggested that inflammation or experimental intestinal obstruction can lead to a significant increase in the number of enteric neurons $(15,16)$. Although these observations suggest that neurogenic cells persist in enteric ganglia of adults, their identity and relationship to embryonic ENS precursors are currently unclear.

Here we combine genetic fate mapping, cultures of dissociated enteric ganglia, and an ENS injury model in mice to prospectively identify ENS progenitors and follow their developmental potential in vivo. Our studies demonstrate that Sox10-expressing enteric neural crest cells are highly neurogenic during embryogenesis, but neuronal differentiation is progressively reduced at late embryonic and early postnatal stages. Constitutive neurogenesis is undetectable in the ENS of adult animals, but remarkably, mature glial cells are capable of generating enteric neurons when placed in culture 

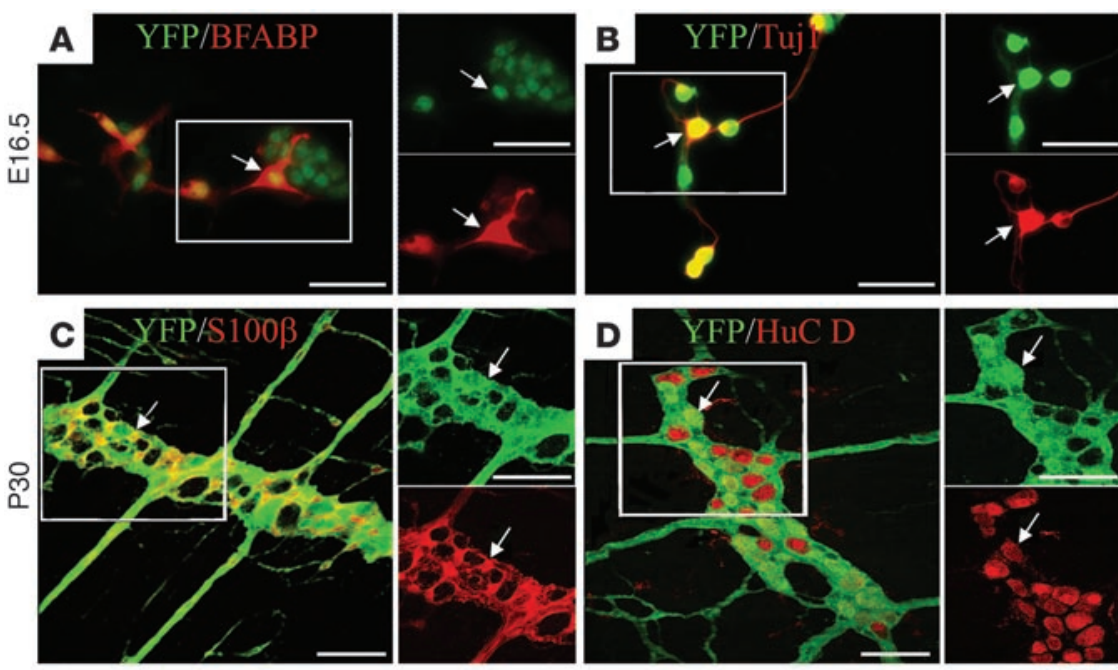

\section{Figure 1}

Enteric neurons and glia are derived from a common pool of Sox10-expressing progenitors. (A and B) Short-term cultures of dissociated gut from E16.5 Sox10::Cre;R26ReYFP transgenic embryos immunostained for YFP (green) and (in red) either the glial marker BFABP $(\mathbf{A})$ or the neuronal marker TuJ1 (B). (C and D) Whole mount preparations of MS-MPs from P30 animals of the same genotype immunostained for YFP (green) and (in red) either the glial marker $\mathrm{S} 100 \beta$ (C) or the neuronal marker HuC/D (D). Arrows indicate double-positive cells. (E) Quantification of the fraction of YFP+ ${ }^{+}$cells that belong to the neuronal of glial lineage of the ENS. Error bars indicate SEM. Scale bars: $30 \mu \mathrm{m}$ (A and $\mathbf{B}$, insets of $\mathbf{A}$ and $\mathbf{B}), 60 \mu \mathrm{m}(\mathbf{C}$ and $\mathbf{D}$, insets of $\mathbf{C}$ and $\mathbf{D}$ ).
$\mathbf{E}$

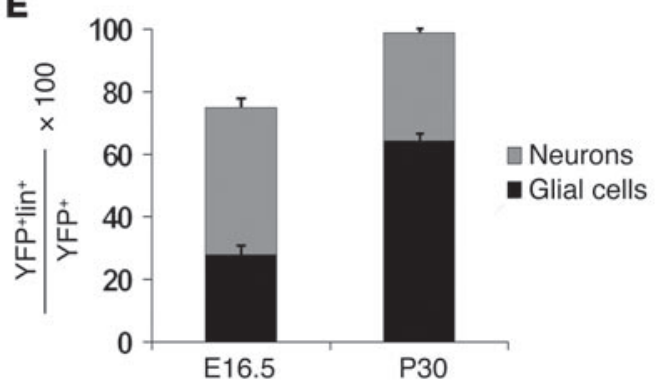

and in response to injury in vivo. Our data provide a framework for exploring the molecular mechanisms that control enteric neurogenesis in vivo and identify glial cells as a potential target for cell replacement therapies in diseases associated with congenital absence or acquired loss of enteric neurons.

\section{Results}

Sox10-expressing cells give rise to enteric neurons and glia in vivo. To examine the lineage relationship between Sox10-expressing neural crest cells and enteric neurons and glia, we fate mapped Sox $10^{+}$cells in vivo by combining a Sox10::Cre transgene (17) with the Cre-dependent R26ReYFP reporter (18). As expected, whole mount YFP immunostaining of E12.5 Sox10::Cre;R26ReYFP embryos showed expression of YFP in derivatives of neural crest cells, such as cranial sensory ganglia, dorsal root ganglia (DRG), sympathetic chain, and ENS (data not shown and Supplemental Figure 1; supplemental material available online with this article; doi:10.1172/JCI58200DS1). The efficiency of Cre-mediated recombination in the ENS of Sox 10::Cre;R26ReYFP mice was established by immunostaining short-term cultures of dissociated gut from E16.5 embryos for YFP and Sox10. YFP expression was detected in $82.7 \% \pm 4.2 \%$ (391 cells, $n=3$ ) of Sox $10^{+}$cells (Supplemental Figure 1 ), indicating that this double-transgenic system marks the majority of Sox10-expressing cells within the gastrointestinal tract.

To fate map Sox10-expressing cells in the ENS of Sox10:: Cre;R26ReYFP embryos, we analyzed coexpression of YFP and appropriate lineage markers either in short-term cultures of dissociated gut from E16.5 embryos or on whole mount preparations of muscle strips with adherent myenteric plexus (MS-MP) from P30 animals. At E16.5, 27.8\% $\pm 2.9 \%$ (523 cells, $n=3$ ) of $\mathrm{YFP}^{+}$cells expressed the glial marker brain fatty acid-binding protein (BFABP) (19), whereas nearly half of $\mathrm{YFP}^{+}$cells expressed the pan-neuronal marker Tuj1 $(47.1 \% \pm 4.7 \% ; 514$ cells, $n=3$ ) (Figure $1, \mathrm{~A}, \mathrm{~B}$, and $\mathrm{E})$. At this stage, approximately $25 \%$ of $\mathrm{YFP}^{+}$cells were not labeled by either glial or neuronal markers, suggesting that they represented uncommitted progenitors. At P30, 64.3\% $\pm 2.3 \%$ (1,981 cells, $n=3$ ) of $\mathrm{YFP}^{+}$ cells coexpressed the glial marker S100 $\beta$ (19), while $34.4 \% \pm 3.7 \%$ expressed the neuron-specific RNA binding protein $\mathrm{HuC} / \mathrm{D}(2,180$ cells, $n=3$ ) (ref. 20 and Figure 1, C-E). In contrast to E16.5 embryos, only approximately $1 \%$ of $\mathrm{YFP}^{+}$cells in the gut of $\mathrm{P} 30$ double-transgenic mice were negative for both neuronal and glial markers, suggesting that by this postnatal stage, most Sox10-expressing cells in the mouse gut have differentiated along the neuronal or glial lineage. Finally, no colocalization between YFP and the myofibroblast marker SMA (21) was detected in the gut of Sox10::Cre;R26ReYFP animals ( 644 cells, 3 E16.5 mice; 527 cells, 3 P30 mice). These findings demonstrate that enteric neurons and glia are derived in vivo from a common pool of Sox10-expressing progenitors.

Stage-specific lineage labeling of Sox10-expressing ENS progenitors. To explore the dynamic changes in the developmental potential of ENS progenitors during pre- and postnatal stages, we generated transgenic mice expressing a tamoxifen-inducible form of Cre recombinase (iCreER ${ }^{\mathrm{T} 2}$ ) (22) under the control of Sox10 regulatory sequences (Sox10::iCreER ${ }^{T 2}$ transgene). For this, a $170-\mathrm{kb}$ phage artificial chromosome (PAC) containing $62 \mathrm{~kb}$ upstream and $57 \mathrm{~kb}$ downstream of the Sox10 gene (17) was modified by replacement of the coding region of Sox 10 with $i C_{r e E R}{ }^{T 2}$ (ref. 23, Figure 2A, and Methods). Mice transgenic for the modified PAC were crossed to the R26ReYFP reporter strain to generate 4 Sox10::iCre $\underline{E R}^{T 2} ; R 26 R e Y F P$ transgenic lines, called 

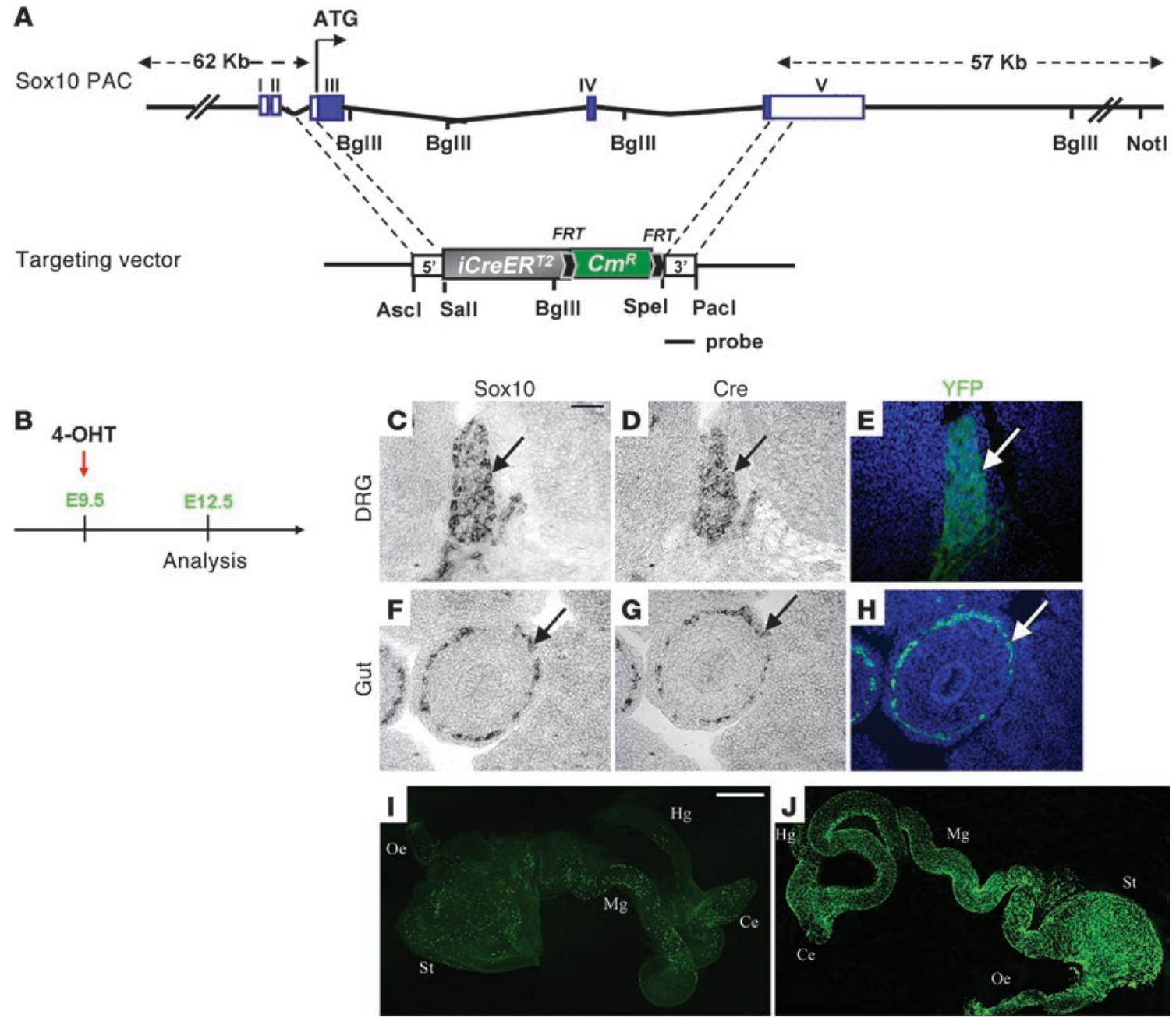

Figure 2

Tamoxifen-dependent induction of YFP in Sox10::iCreERT2;R26ReYFP embryos recapitulates Sox10 expression. (A) Targeting strategy for generating the Sox10::iCreERT2 transgene. Top: Schematic representation of the 170-kb Sox10 PAC. White and blue boxes represent noncoding and coding exons, respectively, and solid lines represent introns and flanking DNA sequences. The start of the coding sequence is shown (ATG). Relative positions of Bglll and Notl restriction enzyme sites are shown. Bottom: Targeting cassette, which includes $5^{\prime}$ and $3{ }^{\prime}$ homology regions (white boxes), the CreERT2 coding sequence (gray box), and the chloramphenicol resistance (Cmr) gene (green box) flanked by FRT sites (black arrows). Relative positions of Ascl, Bglll, Sall, Spel, and Pacl restriction sites and the location of the 3' UTR probe used for Southern blot analysis of Bglll-digested DNA are depicted. (B) Pregnant females were administered 4-OHT (0.2 mg/g) at E9.5, and Sox10:: iCreER ${ }^{T 2} ; R 26 R$ RFF embryos were harvested and analyzed at E12.5. (C-H) Serial sections from Sox10::iCreER ${ }^{\text {T2; }}$ R26ReYFP embryos were hybridized with Sox10- or Cre-specific riboprobes (C, D, F, and G) or immunostained for YFP (E and $\mathbf{H})$. Sections in $\mathbf{C}-\mathbf{E}$ represent DRG, while sections in F-H represent the gut. (I and J) YFP immunostaining of whole mount preparations of gut from control (I) or tamoxifen-treated E12.5 embryos $(\mathbf{J})$. Note the dramatic increase in the number of YFP-expressing cells in the gut of embryos exposed to tamoxifen. Oe, esophagus; St, stomach; Mg, midgut; Ce, cecum; Hg, hindgut. Scale bars: $50 \mu \mathrm{m}(\mathbf{C}-\mathbf{H})$ and $600 \mu \mathrm{m}$ (I and J).

SER26, SER68, SER87, and SER93. The data presented in this report were obtained with the SER2 6 transgenic line but have been confirmed by analysis of additional lines.

To establish that the Sox $10:: i C r e E R^{T 2}$ transgenes reflect the expression of the Sox10 locus, we performed in situ hybridization using Sox10- and Cre-specific riboprobes on adjacent sections of E12.5 SER26 embryos. Cre transcripts were restricted to structures expressing Sox10, such as DRG and the ENS (Figure $2, \mathrm{C}, \mathrm{D}, \mathrm{F}$, and G). Moreover, administration of $0.2 \mathrm{mg} / \mathrm{g}$ of 4-hydroxytamoxifen (4-OHT) at E9.5 resulted in YFP expression at these sites (Figure 2, B, E, and H). Indeed, in embryos and adult animals of all 4 transgenic lines, YFP was detected in established sites of Sox 10 expression and in tissues derived from Sox10-expressing progenitors (Supplemental Figure 2 and data not shown).

To further examine whether the Sox10::iCreER $R^{T 2}$ transgene can temporally activate the R26ReYFP reporter within the ENS, we analyzed YFP expression in the gut of E12.5 SER26 embryos treated with 4-OHT at E9.5. Relative to controls, the gut of 4OHT-treated embryos contained a dramatically larger number of YFP-expressing cells (Figure 2, I and J). To quantify this effect, we immunostained dissociated gut cultures from control and 4- 

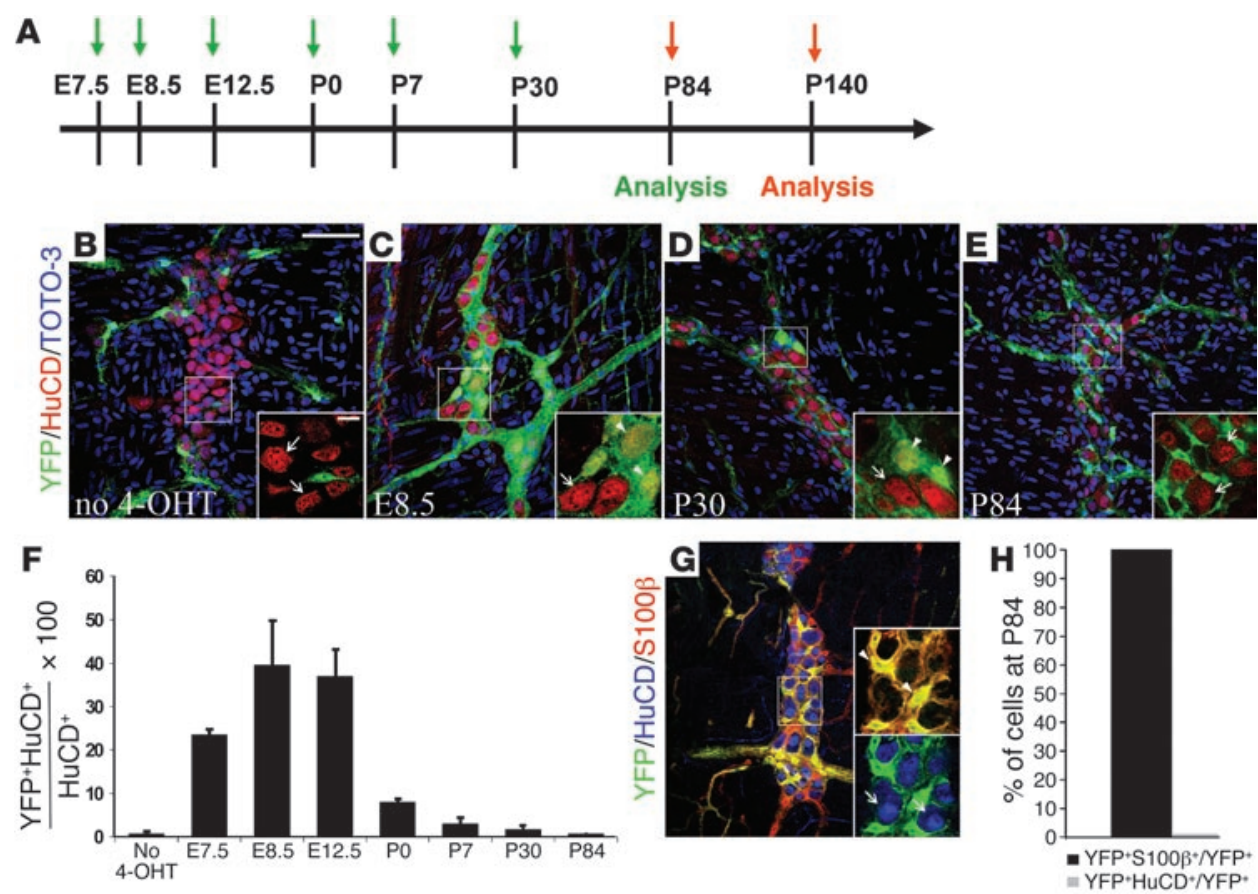

Figure 3

Temporal changes in the neurogenic potential of Sox10-expressing eNCSCs. (A) 4-OHT $(0.2 \mathrm{mg} / \mathrm{g})$ was administered to pregnant females or postnatal animals, and the gut of SER26 transgenic mice was analyzed at P84 (for injections at E7.5, E8.5, E12.5, P0, P7, and P30) or P140 (for injections at P84). (B-E) Laser confocal microscopy images of representative whole mount MS-MP preparations from SER26 animals immunostained for YFP (green) and HuC/D (red) and counterstained with TOTO-3 (blue nuclear marker). MS-MP preparations were from P84 (B-D) or P140 (E) mice that were either not treated (B) or treated with 4-OHT at the indicated time points (C-E). Arrowheads indicate double-positive (YFP+HuC/D+) cells, which correspond to neurons generated after 4-OHT administration. Arrows indicate YFP-HuC/D+ cells. (F) Quantification of the fraction of $\mathrm{HuC} / \mathrm{D}^{+}$neurons coexpressing YFP in the gut of P84 or P140 animals. Shown on the $x$ axis are the time points of 4-OHT administration. (G) Laser confocal microscopy images of MS-MP preparations from P140 SER26 animals (tamoxifen administration at P84) immunostained for YFP (green), HuC/D (blue), and S100 $\beta$ (red). Insets are magnification of the boxed area showing YFP+HuC/D-S100 $\beta^{+}$ cells (arrowheads). Arrows indicate YFP-HuC/D+ neurons. (H) Quantification of the fraction of HuC/D+ and S100 $\beta^{+}$cells within the YFP+ cell population. Error bars indicate SEM. Scale bars: $60 \mu \mathrm{m}$ (B-E and $\mathbf{G}$ ) and $10 \mu \mathrm{m}$ (insets of B-E and $\mathbf{G}$ ).

OHT-treated embryos for Sox 10 and YFP. Upon administration of 4 -OHT, $87.9 \% \pm 8.6 \%$ of the Sox $10^{+}$cells of SER 26 embryos $(1,177$ cells, $n=3)$ expressed the YFP reporter, but only $3.4 \% \pm$ $1.1 \%(1,219$ cells, $n=3)$ of the Sox $10^{+}$cells were $\mathrm{YFP}^{+}$in control embryos (data not shown). These experiments, demonstrating a tamoxifen-dependent and cell type-specific activation of Cre recombinase in SER26 mice, establish a genetic system in which Sox10-expressing progenitors can be lineally marked at specific developmental stages in vivo.

The neurogenic potential of Sox10-expressing cells decreases after midgestation. Having developed a genetic system that marks Sox $10^{+}$ cells at a given developmental stage, we next explored the temporal dynamics of neurogenesis by Sox10-expressing ENS progenitors at pre- and postnatal stages. To this end, SER26 animals were exposed to 4-OHT at different developmental stages, and the identity of lineally marked progeny within the gut was established by double immunostaining of adult MS-MP preparations for YFP and appropriate lineage markers. More specifically, tamoxifen was administered at E7.5, E8.5, E12.5, P0, P7, P30, and $\mathrm{P} 84$, and the population of enteric neurons generated from the lineally marked Sox $10^{+}$progenitors was examined at P84 (for 4OHT administered between E7.5 and P30) or P140 (for 4-OHT administered at P84) (Figure 3A). In the absence of 4-OHT, only
$0.6 \% \pm 0.8 \%$ of $\mathrm{HuC} / \mathrm{D}^{+}$cells $(1,589$ cells, $n=3)$ were colabeled for YFP, consistent with low background levels of Cre activity (Figure 3, B and F). However, when 4-OHT was administered at E7.5, $23.5 \% \pm 1.5 \%$ of the $\mathrm{HuC} / \mathrm{D}^{+}$neurons coexpressed YFP (1,280 cells, $n=3)$, indicating that approximately a quarter of enteric neurons found in the gut of P84 mice are generated from Sox10-expressing progenitors in E7.5-E8.0 embryos (Figure 3F). Sox10+ cells present in E8.5-E9.0 embryos (4-OHT injections at E8.5) generated $39.5 \% \pm 10.6 \%(3,013$ cells, $n=5)$ of enteric neurons in P84 animals (Figure 3, C and F). However, this fraction was progressively reduced at later stages: $36.9 \% \pm 6.4 \%(1,606$ cells, $n=4)$ of adult enteric neurons were derived from Sox $10^{+}$progenitors found in the gut of E12.5-E13.0 embryos, and only 7.8\% $\pm 1 \%$ (2,748 cells, $n=4$ ) of neurons were generated from P0 progenitors (Figure $3 \mathrm{~F}$ ). An even smaller fraction of enteric neurons was generated from Sox $10^{+}$progenitors that persist at postnatal stages: $2.8 \% \pm 1.7 \%$ $(2,471$ cells, $n=3)$ were generated from P7 progenitors and $1.6 \%$ $\pm 1.1 \%$ (3,579 cells, $n=4)$ from P30 progenitors (Figure 3, D and F). Finally, animals treated with 4-OHT at P84 (0.6\% $\pm 0.2 \% ; 3,457$ cells, $n=4)$ showed no YFP-labeled enteric neurons above background levels when analyzed at P140 (Figure 3, E and F), indicating that by this stage no neurons are generated by Sox10-expressing cells. Indeed, we found that all YFP-expressing cells in the 

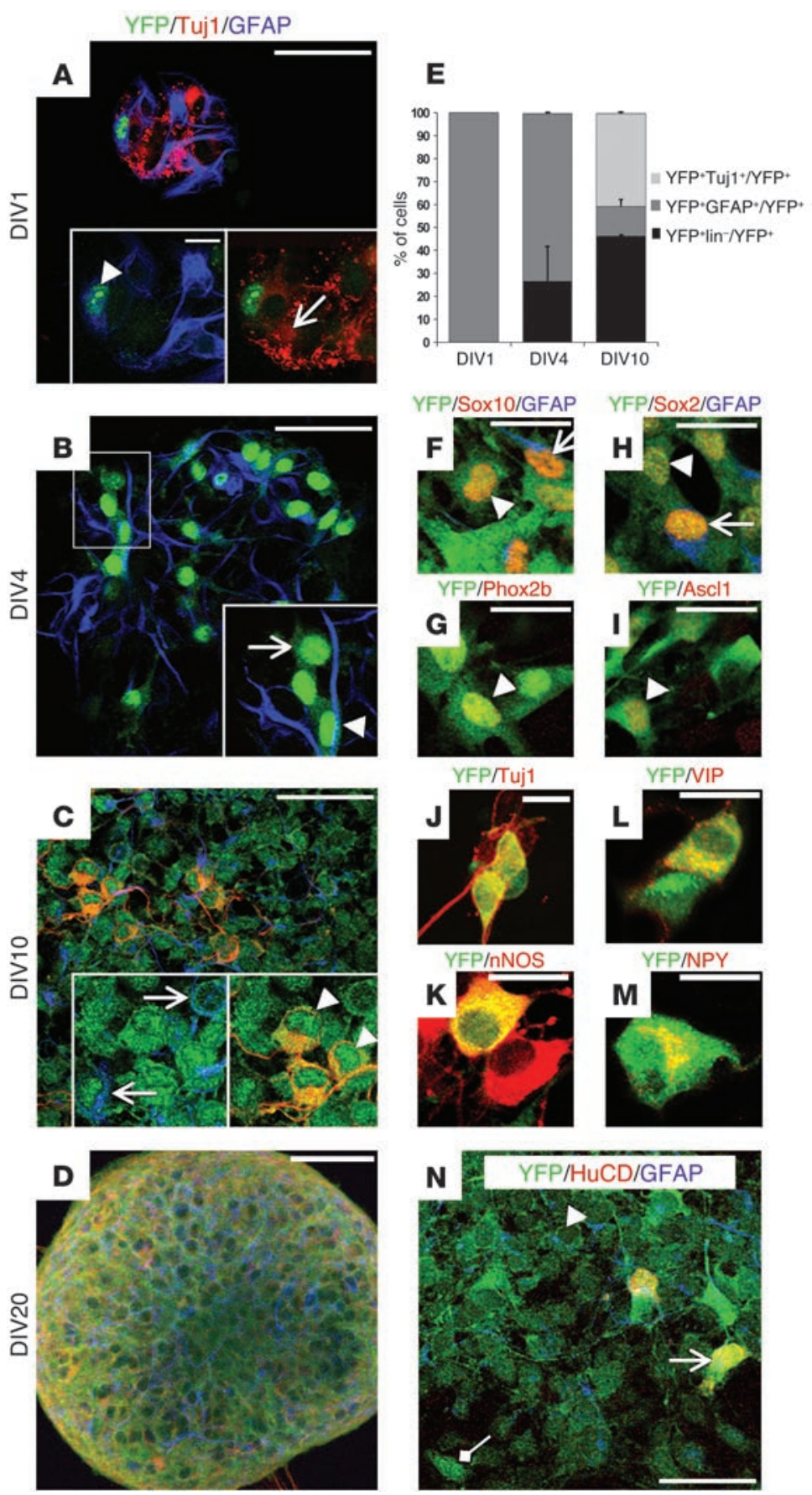

\section{Figure 4}

$\mathrm{YFP}^{+}$glia from the ENS of adult SER26 mice generate neurons in culture. (A-D) MS-MP cultures from 4-OHT-treated SER26 mice immunostained for YFP (green), TuJ1 (red), and GFAP (blue) at 12 hours (A), 4 days (B), 10 days (C), and 20 days (D) after plating. On DIV1, all YFP+ cells coexpressed GFAP (arrowhead in A), and all Tuj $1^{+}$neurons were YFP(arrow in A). On DIV4, the $\mathrm{YFP}^{+}$population includes glial (YFP+Tuj1-GFAP+) and non-glial non-neuronal (YFP+Tuj1-

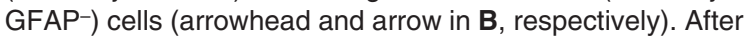
10 DIV, YFP+ cells include glia (arrows in C), non-glial nonneuronal cells, and neurons (YFP+Tuj1+GFAP-; arrowheads in C). On DIV20, most YFP+ cells are found in NLBs. (E) Quantification of the fraction of neurons and glia in the YFP+ population of DIV1, DIV4, and DIV10 cultures. Error bars indicate SEM. (F-I) DIV4 cultures immunostained for YFP and GFAP and Sox10 (F), GFAP and Sox2 (H), Phox2B (G), and Ascl1 (I). Sox10 and Sox2 were expressed by YFP+GFAP+ cells as well as by $\mathrm{YFP}^{+} \mathrm{GFAP}^{-}$cells (arrows and arrowheads, respectively, in $\mathbf{F}$ and $\mathbf{H}$ ). (J-M) Immunostaining of DIV10 cultures for YFP and Tuj1 (J), nNOS (K), VIP (L), and NPY (M). (N) Immunostaining of 6-month-old cultures for YFP, HuC/D, and GFAP. In these cultures the YFP+ population included

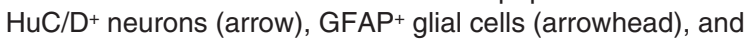
HuC/D-GFAP- cells (diamond arrow). Scale bars: $60 \mu \mathrm{m}$ (AD, N), $10 \mu \mathrm{m}$ (F-I), $10 \mu \mathrm{m}$ (J), $10 \mu \mathrm{m}$ (K-M).

$\mathrm{YFP}^{+}$cells from the gut of adult SER26 animals acquire neurogenic properties in culture. Our failure to detect neurogenesis by Sox $10^{+}$cells in the gut of adult mice raises the question of the origin of the multipotential ENS progenitors isolated from cultures of adult gut $(13,14)$. The possibility that the source of these neurons is a small residual population of non-glial Sox $10^{+}$progenitors persisting within enteric ganglia after completion of enteric neurogenesis is not consistent with the finding that YFP was expressed exclusively in glial cells in our Sox10-driven reporter system (Figure 3, G and H). Therefore, we tested the hypothesis that mature enteric glial cells can exhibit neurogenic potential under certain conditions. For this, MS-MP preparations from SER26 adult mice (in which glial cells can be lineally marked) were dissociated 1 week after 4OHT administration at P84 and cultured under conditions that promote the proliferation and self-renewal of ENS progenitors $(8,21,24)$. Time course analysis of these cultures confirmed that within 12 hours after plating (day in vitro 1 [DIV1]), virtually all $\mathrm{YFP}^{+}$cells coexpressed the glial marker glial fibrillary acidic protein (GFAP; 428 cells, $n=3$ ), while the neuronal marker TuJ1 was present exclusively in YFP- cells (Figure 4, A and E). At DIV4, YFP ${ }^{+}$ cells had increased in number and formed small colonies

myenteric plexus of animals exposed to 4-OHT at P84 represent S100 $\beta$-expressing glial cells (3,081 cells, $n=4)$ (Figure 3, G and H). At this stage the efficiency of recombination of the fluorescent reporter was consistently greater than 50\% (data not shown). For all the time points considered, the difference in the proportion of YFP-labeled cells in the $\mathrm{HuC} / \mathrm{D}^{+}$population between different regions of the small intestine was not statistically significant (data not shown). These experiments suggest that the neurogenic potential of Sox $10^{+}$progenitors in the mammalian gut is highest at mid-gestation but is subsequently reduced and becomes undetectable in adult animals. that were morphologically similar to the colonies generated by embryonic eNCSCs (refs. 8, 24, and Figure 4B). These colonies contained on average $9.6 \pm 6.3$ cells, the majority, of which $(73.2 \% \pm$ $11.3 \%$ ) coexpressed the glial marker GFAP. However, $26.5 \% \pm 10.9 \%$ of $\mathrm{YFP}^{+}$cells expressed neither glial (GFAP) nor neuronal (Tuj1) markers (246 cells, $n=3$ ), raising the possibility that they represent glial-derived eNCSCs (Figure 4, B and E). Consistent with this idea, most of the $\mathrm{YFP}^{+} \mathrm{GFAP}^{-}$cells in DIV4 colonies were colabeled for Sox 10, Phox2b (19, 25), and Sox2 (ref. 26 and Figure 4, F-I). In addition, a fraction of $\mathrm{YFP}^{+}$cells in DIV4 colonies expressed Ascl1 (Mash1) (Figure 4I), a proneural gene that is expressed transiently 

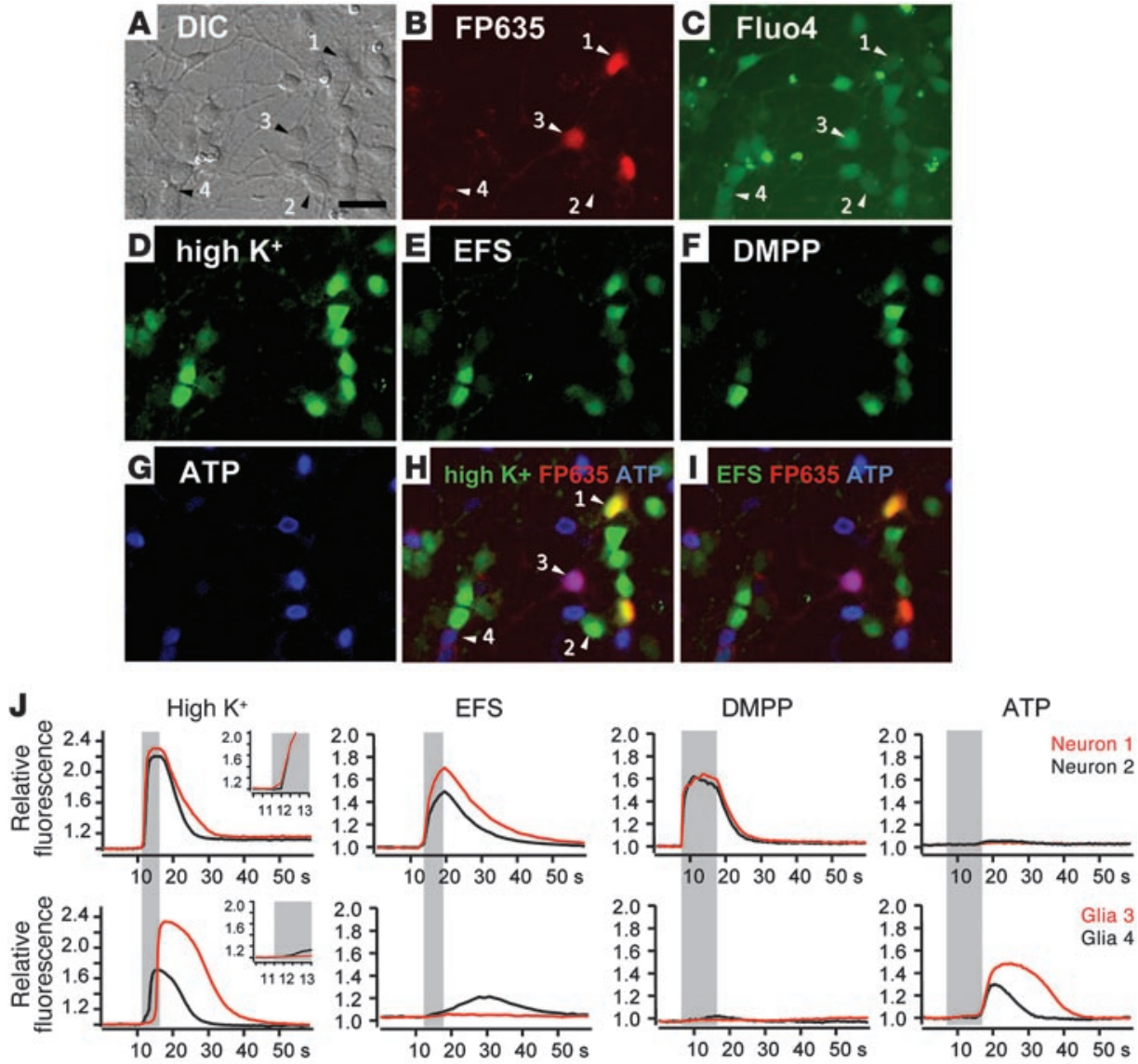

\section{Figure 5}

Enteric glial cells generate functional neurons in vitro. (A) DIC image of enteric glial cell culture established from Sox10::iCreER ${ }^{T 2}$;R26R ${ }^{F P 635}$ mice. Numbers 1-4 indicate cells that are studied in detail. (B) Fluorescence image (recorded at $620 / 50 \mathrm{~nm}$ ) of the cells shown in $\mathbf{A}$. Note that cells 1 and 3 express the fluorescent protein FP635. (C) Fluo-4 signal (recorded at 525/50 $\mathrm{nm}$ ) of the culture before stimulation. Note low background levels of signal in cells 1-4. (D-G) AoT images in which only pixels responding to high $\mathrm{K}^{+}(\mathbf{D})$, EFS (E), and application of DMPP (F) and ATP $(\mathbf{G})$ are shown. (H) Merge of images in B, D, and $\mathbf{G}$. (I) Merge of images in $\mathbf{B}, \mathbf{E}$, and $\mathbf{G}$. (J) Recordings of the responses of neurons 1 (red) and 2 (black) and glia 3 (red) and 4 (black) to high $\mathrm{K}^{+}$, EFS, DMPP and ATP. Neuron 1 and glia 3 express FP635. Insets show the fast upstroke in neuronal cells to high $\mathrm{K}^{+}$, compared with a slow secondary response in glial cells. Neurons typically show a fast response to high $\mathrm{K}^{+}$, EFS and DMPP, while glial cells show a slow response to high $\mathrm{K}^{+}$and ATP. (K) Average response of FP635+ (red) and negative neurons to high $\mathrm{K}^{+}$. (L) Average response of $\mathrm{FP} 65^{+}$(red) and FP635- neurons to EFS. Scale bars: $20 \mu \mathrm{m}$.
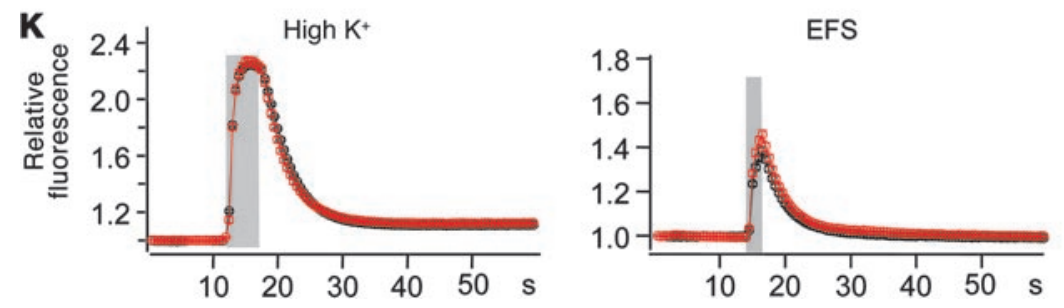

in a subset of enteric neuron precursors (27). These findings suggest that cultured enteric glia are capable of generating multilineage ENS progenitors and activating neurogenic programs.

To further examine whether such putative progenitors are capable of generating mature enteric neurons, DIV7 adult gut cultures were shifted to differentiating conditions (laminin substrate and Neurobasal medium). Three days later (DIV10), we observed that $40.5 \% \pm 3.8 \%$ of $\mathrm{YFP}^{+}$cells coexpressed the pan-neuronal markers Tuj1 or $\mathrm{HuC} / \mathrm{D}, 46.1 \% \pm 0.6 \%$ expressed no lineage (neuronal or glial) marker, and $11 \% \pm 3.3 \%$ coexpressed GFAP ( 265 cells, $n=3$; Figure 4, C, E, and J). Interestingly, $\mathrm{YFP}^{+}$neurons also expressed markers of enteric neuron subtypes, such as neuronal NOS (nNOS), vasoactive intestinal peptide (VIP), and neuropeptide $\mathrm{Y}$ (NPY), suggesting that $\mathrm{YFP}^{+}$cells have the ability to generate neurons that express neurotransmitters found in the ENS (ref. 28 and Figure 4, K-M). As in dissociated embryonic gut (8), after several days in culture $\mathrm{YFP}^{+}$cells started to pile up, and, by day 20, most were found within neurosphere-like bodies (NLBs), which eventually detached and floated in the medium (Figure 4D). $\mathrm{YFP}^{+}$cells could be propagated without loss of expression of the reporter for at least 25 passages, and they were kept in culture for up to 6 months. Even in these late cultures, the $\mathrm{YFP}^{+}$population included many cells that were $\mathrm{YFP}^{+} \mathrm{HuC} / \mathrm{D}^{-} \mathrm{GFAP}^{-}$(Figure $4 \mathrm{~N}$ ), suggesting that they have the capacity to self renew.

Similar results were obtained using $h G F A P:: C r e E R^{T 2} ; R 26 R e Y F P$ mice (29), in which Cre was specifically activated in 19\% $\pm 7.4 \%$ (988 cells, $n=5$ ) of enteric glial cells (Supplemental Figure 3). Taken together, these studies indicate that although Sox10-expressing progenitors of the mammalian ENS lose their neurogenic capacity in vivo and differentiate into glial cells, under certain conditions they can reactivate their neurogenic potential and differentiate into mature enteric neurons.

Glial cells can generate functional synapse-forming neurons in culture. To investigate whether the glia-derived neurons displayed functional neuronal properties, we used Fluo- $4 \mathrm{Ca}^{2+}$ imaging to monitor neuronal activity in ENS cultures (30). To avoid the spectral overlap between the $\mathrm{Ca}^{2+}$ indicator and the YFP lineage reporter, we generated additional mouse lines that carry the Sox10::iCreER ${ }^{T 2}$ 

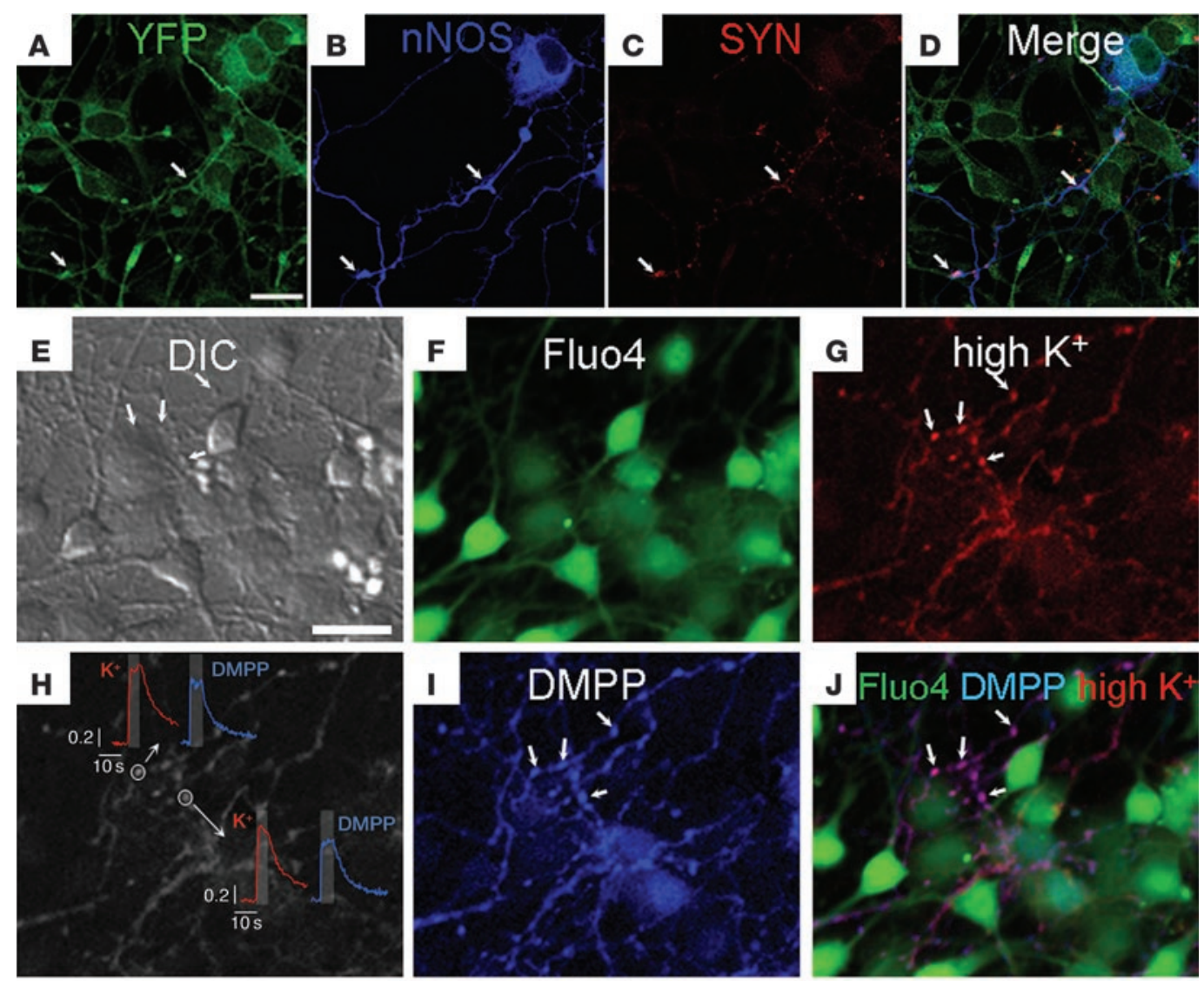

\section{Figure 6}

Glial cells generate synapse-forming neurons in vitro. (A-D) Fluorescence images of the same field of view of an ENS culture established from adult (>P84) 4-OHT-treated SER26 animals. Culture was immunostained for YFP (A), nNOS (B), and synaptophysin (SYN; C). A merge of images in $\mathbf{A}-\mathbf{C}$ is shown in $\mathbf{D}$. Arrows indicate a YFP+nNOS+ neuron that exhibits punctuate expression of the synaptic protein synaptophysin. (E) DIC image of an ENS culture established from Sox10::iCreER ${ }^{T 2} ; R 26 R^{F P 635}$ mice. Arrows point to varicosities analyzed in detail in the other panels. (F) Fluo-4 image without stimulation. $(\mathbf{G})$ AoT at the varicosities indicated in $\mathbf{E}$ upon high- $\mathrm{K}^{+}$stimulation. (H) Typical Ca ${ }^{2+}$ transients in the indicated neuronal varicosities following high- $\mathrm{K}^{+}(\mathrm{red})$ and DMPP (blue) stimulation. (I) AoT of DMPP stimulation. (J) Merge of images in $\mathbf{F}$, $\mathbf{G}$, and I in which the varicose nerve fiber is visible in purple. Scale bars: $20 \mu \mathrm{m}$.

transgene and the $R 26 R^{F P 635}$ allele, which is capable of expressing the red fluorescent protein FP635 (31) in a Cre-dependent manner (for the generation of the R26R FP635 allele, see Methods). ENS cultures were established from MS-MP strips of adult (>P84) tamoxifen-treated Sox 10::iCreER ${ }^{T 2} ; R 26 R^{F P 635}$ transgenics, and patches of neuronal cells were identified morphologically using differential interference contrast (DIC) microscopy (Figure 5A). After Fluo-4 loading, all cells displayed dim green fluorescence (Figure 5C), while some of them expressed FP635, indicating that they derived from glial cells (Figure 5B).

A brief depolarization of cultured enteric neurons with high $\mathrm{K}^{+}$ ( 5 seconds, $75 \mathrm{mM}$ ) causes an immediate $\mathrm{Ca}^{2+}$ influx, resulting in a sharp increase in fluorescence that reaches maximum values in less than 2 seconds before decaying exponentially (30). The fast $\mathrm{Ca}^{2+}$ response to $\mathrm{K}^{+}$depolarization is a characteristic feature of enteric neurons that distinguishes them from glia, which show a delayed response ( 7 seconds required to reach the maximum) (32). Enteric neurons also show a robust response to electrical field stimulation (EFS, $20 \mathrm{~Hz}, 2$ seconds, $20 \mathrm{~mA}$ ) and the nicotinic agonist dimethylphenylpiperazinium (DMPP; $10^{-5} \mathrm{M}$ ) (32). Application of ATP $\left(10^{-5} \mathrm{M}\right)$ on the other hand can be used to confirm glial cell identity (32). Using these stimuli, a neuronal $\mathrm{Ca}^{2+}$ signaling fingerprint could be determined, which is defined by a strong and fast response to high $\mathrm{K}^{+}$, EFS, and DMPP and no or delayed response to ATP. For enteric glia, the opposite is true. Figure 5 shows the responses of 4 cells (numbered 1-4), which, based on the expression of FP635 and morphological characteristics, were identified as: cell 1, FP635 neuron; cell 2, FP635- neuron; cell 3, FP635 glia; cell 4, FP635- glia. Images of these cells following exposure to the various stimuli are shown in Figure 5D (high $\mathrm{K}^{+}$), Figure 5E (EFS), Figure 5F (DMPP), and Figure 5G (ATP). The time course of $\mathrm{Ca}^{2+}$ responses for the 4 cells is shown in Figure 5J. In total we have analyzed a group of 74 cells, 34 of which were positively identified as neurons $\left(14 \mathrm{FP} 635^{+}\right.$and $\left.20 \mathrm{FP} 635^{-}\right)$and 40 as glia $\left(17 \mathrm{FP} 635^{+}\right.$and $\left.23 \mathrm{FP} 635^{-}\right)$. The characteristic $\mathrm{Ca}^{2+}$ signaling fingerprint was present in the majority of $\mathrm{FP} 635^{+}$neurons. Challenged with high $\mathrm{K}^{+}$, all neurons displayed the typical fast response, which did not differ in amplitude or duration between control and FP635-expressing neurons (Figure $5 \mathrm{~K}$ ). EFS elicited $\mathrm{Ca}^{2+}$ transients in $75 \%$ of analyzed neurons (24 of 34, $n=3$ ), which was not different between FP635' and FP635- cells (65\%, 9 of $14, P=0.4, \chi^{2}$ test). Also, the amplitude of the response in the two groups was similar (Figure 


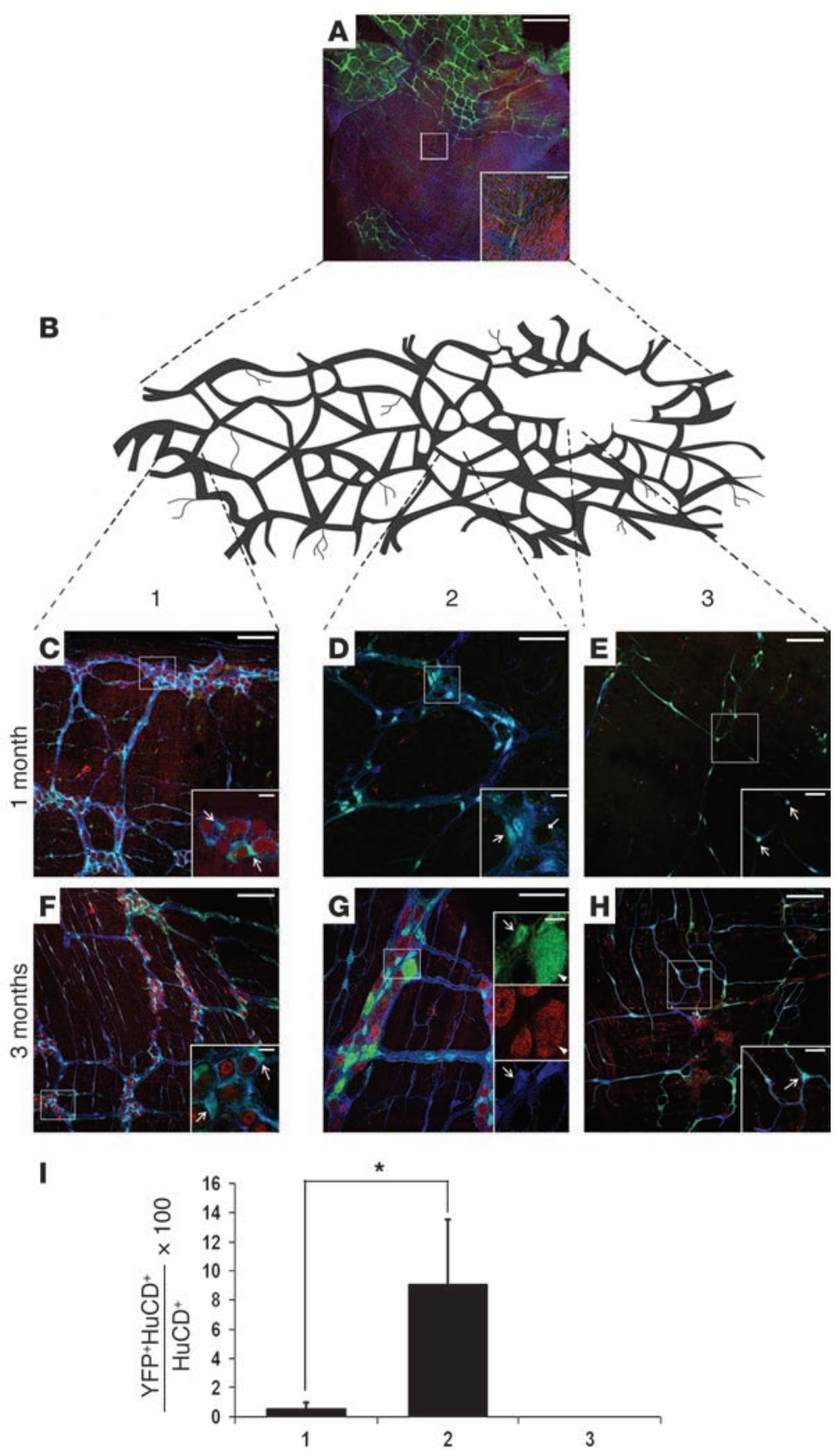

\section{Figure 7}

$\mathrm{YFP}^{+}$glial cells from the ENS of adult SER26 mice can generate neurons in vivo. (A) Laser confocal microscopy of MS-MP preparations from the gut of 4-OHT- and BACtreated SER26 mice (P84 or older). Inset shows absence of $\mathrm{YFP}^{+}, \mathrm{HuC} / \mathrm{D}^{+}$, or $\mathrm{S} 100 \beta^{+}$cells in the treated area. (B) Schematic representation of enteric plexus that includes an area that as a result of BAC treatment becomes aganglionic (area 3). (C-H) Laser confocal microscope images of MS-MP preparations representing areas of the enteric plexus that are located distant to (area 1; C and F), adjacent to (area 2; $\mathbf{D}$ and $\mathbf{G}$ ), or within the BAC-treated area of the gut (area 3; $\mathbf{E}$ and $\mathbf{H}$ ) and analyzed 1 month $(\mathbf{C}-\mathbf{E})$ or 3 months $(\mathbf{F}-\mathbf{H})$ after BAC treatment. MS-MP strips were immunostained for YFP (green), HuC/D (red), and S100 $\beta$ (blue). Arrowheads in insets of $\mathbf{G}$ indicate $\mathrm{YFP}+\mathrm{HuC} / \mathrm{D}^{+}$ double-labeled cell. Arrows indicate $\mathrm{YFP}+\mathrm{HuC} / \mathrm{D}^{-} \mathrm{S} 100 \beta^{+}$ cells. Diamond arrow in $\mathbf{D}$ indicates space within the ganglia suggesting that neuron loss has occurred. (I) Quantification of the fraction of $\mathrm{YFP}+\mathrm{HuC} / \mathrm{D}^{+}$cells in areas 1 , 2 , and 3 . Note that the fraction of $\mathrm{YFP}^{+}$neurons present within enteric ganglia of area 2 is much greater relative to that in area 1. ${ }^{*} \mathrm{~F}(2)=5.613 ; P=0.03$; ANOVA. Error bars indicate SEM. Scale bars: $600 \mu \mathrm{m}(\mathbf{A}), 100 \mu \mathrm{m}(\mathbf{C}, \mathbf{E}, \mathbf{F}, \mathbf{H}$, and inset of $\mathbf{A}$ ), $60 \mu \mathrm{m}$ (D and $\mathbf{G}$ ), $30 \mu \mathrm{m}$ (insets of $\mathbf{E}$ and $\mathbf{H}$ ), $10 \mu \mathrm{m}$ (insets of $\mathbf{C}, \mathbf{D}$, and $\mathbf{F}$ ), $10 \mu \mathrm{m}$ (insets of $\mathbf{G}$ ).
5L). DMPP elicited clear responses in $80 \%$ (26 of 34) of the neurons, and although the DMPP response amplitude did not differ, the proportion of responders was somewhat lower in the FP635expressing population $\left(57 \%, P=0.02, \chi^{2}\right.$ test). Results of independent $\mathrm{Ca}^{2+}$ imaging experiments with cultures established from SER26 mice were consistent with the data obtained from Sox10:: $i C r e E R^{T 2} ; R 26 R^{\mathrm{FP} 635}$ animals (data not shown).

Enteric neurons in culture establish functional networks with synaptic release sites (33). To investigate whether enteric glia-derived neurons were equally capable of integrating into the neuronal network and establishing functional synaptic connections, we employed immunohistochemical and $\mathrm{Ca}^{2+}$ imaging techniques. More specifically, we analyzed cultures from adult tamoxi- fen-treated SER26 mice to identify sites of neurotransmitter release using the general synaptic vesicle marker synaptophysin (33). Triple labeling for synaptophysin, nNOS, and YFP (indicating glia origin) revealed the presence of synaptic vesicles (Figure 6, A-D) in $\mathrm{YFP}^{+}$ neurons. $\mathrm{Ca}^{2+}$ imaging was used to monitor presynaptic activity in individual varicosities and putative release sites in culture (34). After loading with Fluo-4, characteristic neuronal $\mathrm{Ca}^{2+}$ fingerprints could be recorded from these sites, which showed a fast fluorescent upstroke to depolarization (high $\mathrm{K}^{+}$) and to the nicotinic agonist DMPP (Figure 6, G-I). All cells, including neurons, shown in Figure $6, \mathrm{E}-\mathrm{J}$, were $\mathrm{YFP}^{+}$, and thus of glial origin. Together, these findings suggest that enteric glia cells from adult animals are capable of generating functional enteric neurons in culture. 
$\mathrm{YFP}^{+}$glial cells generate neurons in vivo after injury. Next we examined whether enteric glia exhibit neurogenic potential in vivo. Since we could not detect neurogenesis in the ENS of adult (>P84) SER26 transgenic mice (Figure 3), we hypothesized that the neurogenic potential of enteric glial cells may be revealed only upon disruption of tissue homeostasis. To test this premise, we exploited the Sox10::iCreER ${ }^{T 2}$;R26ReYFP lineage marking system in combination with the cationic detergent benzalkonium chloride (BAC), which ablates locally the myenteric plexus in a dose-dependent manner when applied to the serosal surface of the intestine (35). BAC was applied to a small area of the small intestine of adult SER26 mice (>P84) that had been previously treated with tamoxifen to lineally mark glial cells. MS-MP preparations from the treated and adjacent areas were analyzed at different times after BAC application for expression of YFP, the pan-neuronal marker HuC/D, and the glial marker S100 $\beta$. Consistent with previous reports $(36,37), 3$ days after treatment, enteric ganglia were eliminated from the region of BAC application (Figure 7, A and B). One month later the treated area was colonized by glial cells and was invaded by neuronal projections. No $\mathrm{YFP}^{+}$neurons were found in the aganglionic intestinal segment or in the area adjacent to the BAC-treated region, where most ganglia included $\mathrm{YFP}^{+}$glial cells but no neurons, as assessed by expression of $\mathrm{HuC} / \mathrm{D}(n=3)$. Away from the treated area, we found morphologically normal ganglia containing $\mathrm{YFP}^{-} \mathrm{HuC} / \mathrm{D}^{+}$neurons and $\mathrm{YFP}^{+} \mathrm{S} 100 \beta^{+}$glial cells (Figure 7, C-E). However, when analyzed at approximately 3 months (70-90 days) after BAC treatment, enteric ganglia bordering the aganglionic area contained a relatively large fraction of $\mathrm{YFP}^{+} \mathrm{HuC} / \mathrm{D}^{+}$cells $\left(9.0 \% \pm 4.0 \% ; 3,197 \mathrm{HuC} / \mathrm{D}^{+}\right.$cells, $\left.n=4\right)$, indicating that they derived from YFP-marked glial cells. The percentage of $\mathrm{YFP}^{+}$enteric neurons detected within enteric ganglia was inversely proportional to their distance from the treated area, ranging from $0.5 \%$ (background level at segments distant from treated region) to $9 \%$ (adjacent to the treated area) $(\mathrm{F}[2]=$ 5.613; $P=0.03$; ANOVA; Figure 7, F-I). In control mice, the frequency of $\mathrm{YFP}^{+} \mathrm{HuC} / \mathrm{D}^{+}$neurons throughout the gut was within the expected background levels and comparable to that observed in distally located gut regions of BAC-treated animals. Together, these experiments suggest that enteric glial cells have neurogenic potential in vivo and are capable of generating enteric neurons in response to ENS injury.

\section{Discussion}

Identification and characterization of eNCSCs in vivo are crucial for understanding how their orchestrated self-renewal and differentiation generate functional neuronal networks within the gut. So far, the properties of eNCSCs have been deduced from cell culture and transplantation studies of cells isolated from the gut on the basis of molecular and functional characteristics $(8,13,38)$. Using genetic fate mapping, we demonstrate here that the Sox10expressing neuroectodermal derivatives of the mammalian gut generate both lineages of the mammalian ENS and therefore are likely to represent the eNCSCs in vivo.

The majority of neurons in the adult ENS are derived from Sox10-expressing progenitors that reside in the gut of mid-gestation mouse embryos. As development proceeds, the fraction of enteric neurons generated from increasingly older pools of progenitors is gradually reduced and eventually, at some stage between P30 and P84, no new neurons are generated from the available Sox $10^{+}$ cells. From that point onward, our Sox10-driven reporter system exclusively labels glial cells, as identified by the expression of enteric glia markers, such as GFAP and S100 $\beta$. The total number of Sox10expressing cells within the gut does not decrease over time, but the gradual reduction of neurogenesis is coupled to the increasing representation of gliogenic precursors and glial cells, which also express Sox10 $(19,39)$. The neurogenic to gliogenic switch of Sox $10^{+}$ progenitors could result from changes in the gut microenvironment, or the gradual accumulation of neuron-derived signals that reach levels sufficient to induce gliogenic fates. Alternatively, the observed changes in neurogenic potential may reflect changes in the intrinsic properties of ENS progenitors, which cease to respond to neuron-promoting signals. In support of this view, Kruger et al. have shown that in comparison to embryonic eNCSCs, their postnatal counterparts exhibit decreased sensitivity to the neurogenic effect of BMP4 and increased sensitivity to the gliogenic activity of the Notch ligand Delta-Fc and neuregulin (13).

A similar dynamic profile of neurogenic (high early, low later) and gliogenic (low early, high later) potential of precursors has been observed in other parts of the nervous system, including the cortex. However, in contrast to the CNS, where the generation of neurons and glia are temporally segregated (40), we observed considerable overlap between the periods of enteric neurogenesis and gliogenesis. The first glial precursors appear in the gut at approximately E11.5 (19), but eNCSCs generate new neurons throughout embryogenesis and beyond P30 (ref. 11 and this study). These findings strengthen the idea that new neurons continue to be integrated into the ENS circuitry long after functional neuronal networks have been established in the gut.

The failure of Sox $10^{+}$cells in the gut of P84 animals to generate enteric neurons is in agreement with an extensive series of BrdU incorporation studies described in a companion to the present article, by Joseph et al. (41), and earlier reports that have been unable to identify newly born neurons in the intact adult mammalian ENS $(11,12)$. Therefore, unlike the CNS, which harbors NSCs and sustains neurogenesis throughout life, the ENS of adult animals does not support constitutive neurogenesis. Nevertheless, self-renewing multilineage progenitors of the ENS have been identified in adult intestine (13). Moreover, administration of 5- $\mathrm{HT}_{4}$ agonists induced enteric neurogenesis in adult mice (12). Our present studies suggest that the multilineage progenitors of adult ENS are enteric glial cells that under certain in vitro and in vivo conditions (such as injury) can activate their neurogenic potential and generate enteric neurons. It is currently unclear whether all glial cells in the adult intestine can, under certain conditions, serve as neurogenic precursors and whether neurogenic potential is restricted to a small fraction of cells expressing glial markers.

Once thought to be passive and merely supporting partners of neurons, glial cells have recently emerged as active regulators of many neuronal functions (42). Furthermore, several reports have highlighted the close relationship between NSCs and glia. Ongoing neurogenesis in the CNS is ensured by GFAP-expressing progenitors with morphological and molecular characteristics of astrocytes (43), and glial cells are the source of new neurons in the injured retina (44) and adult carotid body (4). Our findings suggest that in addition to their regulatory and supportive roles, enteric glia may participate, when and if necessary, in neurogenesis. Although the neurogenic potential of enteric glia is likely to remain dormant under the constraints of the adult ENS niche, such potential can be activated when their microenvironment is altered, either by elimination of the niche (e.g., dissociation and culture) or injury of enteric ganglia. 
In culture, neuronal differentiation is preceded by extensive proliferation and de-differentiation of glial cells into a cell type that has molecular and morphological characteristics of multilineage ENS progenitors. It is currently unclear whether proliferation and de-differentiation are critical for activating the neurogenic potential of enteric glia in vivo. Interestingly, a recent report that describes differentiation of cortical astroglia into neurons provides evidence that cell division is not a prerequisite for neuronal differentiation, thus arguing for a direct fate conversion (45). Moreover, we have so far failed to identify non-neuronal non-glial $\mathrm{YFP}^{+}$ cells in the vicinity of the BAC-treated area, as has been observed in culture. We recognize of course that it is currently impractical to follow systematically the dynamics of marker expression by glial cells in response to injury in vivo, and it is possible that such cells are generated in response to BAC treatment but have simply escaped our detection. With these caveats in mind, we suggest that although the initial trigger that activates neurogenesis from glial cells both in vitro and in vivo is similar, the neurogenic script followed subsequently by the responding cells in the two experimental paradigms may be different.

This idea is further supported by our studies using $h G F A P::$ CreER $R^{T 2}$;R26ReYFP transgenic mice, in which tamoxifen administration labels approximately $20 \%$ of enteric glia in adult animals. Although in culture we observed robust activation of the neurogenic potential of adult enteric glia marked by this transgene, we were unable to detect $\mathrm{YFP}^{+} \mathrm{HuC} / \mathrm{D}^{+}$enteric neurons using the chemical injury paradigm employed for the Sox10::CreER ${ }^{T 2}$;R26ReYFP mice (Supplemental Figure 3 and data not shown). These observations are consistent with the findings of Joseph et al. (41) and raise the interesting possibility that the neurogenic glia in the gut of adult mice represent a subset of Sox10-expressing cells that are not marked by the GFAP::Cre transgenes used in the two studies. It is possible that in culture under the influence of strong neurogenic and proliferative signals, most enteric glia can differentiate into neurons, while in vivo neurogenic potential can be activated only in a subset of Sox10-expressing glial cells. Further studies will be necessary to characterize the properties of the putative neurogenic glia in the ENS of adult mice.

What is the nature of the signals that trigger the neurogenic potential of glial cells? We suggest that both in culture and in vivo, the initiating event is related to the disruption of the intercellular interactions that have been established within the tightly packed enteric ganglia and are required to maintain glial cells in a "dormant" state. Such interactions are clearly lost upon dissociation and culture of enteric ganglia. In addition, the cellular partners of glial cells within enteric ganglia may also change in response to BAC treatment, as suggested by our observation that ganglia next to the treated areas appear to have lost many $\mathrm{HuC} / \mathrm{D}^{+}$neurons. Such neuronal loss may be secondary to the elimination of postsynaptic targets in the aganglionic region induced by BAC treatment. Irrespective of the mechanisms, the elimination of neurons in otherwise healthy ganglia is likely to change the "niche" of glial cells, which by "sensing" the absence of neurons in their vicinity can activate their erstwhile neurogenic program.

Although the majority of enteric glia are found within enteric ganglia, our findings do not exclude the possibility that neurogenic precursors in the adult ENS are extraganglionic. Indeed, Liu and colleagues have previously suggested that Sox10-expressing cells located outside the ganglia are capable of generating enteric neurons in response to $5-\mathrm{HT}_{4}$ receptor activation (12). The relationship between the gliogenic precursors identified in our study and the Sox $10^{+}$precursors reported by Liu et al. warrants further investigation. Also, as serotonin is likely to be present in enteric ganglia, it would be interesting to examine whether this factor is sufficient to drive the differentiation of enteric glial cells into neurons in culture and in vivo. Irrespective of the exact source of precursors and the molecular mechanisms that activate their neurogenic potential, our studies indicate that the enteric neurons derived in culture from glial precursors are functional. This conclusion is based on the analysis of intracellular $\mathrm{Ca}^{2+}$ responses (to stimuli such as $\mathrm{K}^{+}$ depolarization and pharmacological and electrical stimulation) of glia-derived neurons and their putative synaptic contacts.

Neuronal degeneration is a common feature in a number of gastrointestinal disorders, such as inflammatory bowel disease (IBD) and post-enteritis irritable bowel syndrome $(46,47)$. The potential link between inflammation and neuronal degeneration was first suggested by early histopathological studies showing that, in the context of inflammation, neuronal degeneration is often accompanied by other abnormalities, including hypertrophy of ganglia and nerve bundles and/or hyperplasia of glial cells (16). However, Joseph et al. (41) were unable to detect neurogenesis by BrdU incorporation in the gut of mice that were inflamed by chemical treatment or bacterial infection. Nonetheless, if neurogenesis occurs without cell division in response to inflammation, perhaps by direct differentiation of enteric glia into neurons, this could have therapeutic implications for the treatment of severe inflammatory conditions of the gut. Understanding the mechanisms that regulate the neurogenic potential of enteric glia could facilitate the design of novel therapeutic strategies for the treatment of conditions associated with congenital absence of enteric neurons, such as Hirschsprung disease.

\section{Methods}

Animals. Generation of the Sox $10::$ Cre and $h G F A P:: C r e E R^{T 2}$ transgenic mice and the R26ReYFP reporter strain have been described previously $(17,18$, 29). Sox10::iCreER ${ }^{T 2}$ transgenic mice were generated by pronuclear injection of a modified PAC expressing a tamoxifen-inducible Cre recombinase (iCreER ${ }^{\mathrm{T} 2}$ ) (48) under the control of Sox10 regulatory sequences. The original PAC (RP21-529-I6 from RPCI mouse PAC library 21, UK HGMP Resource Centre; ref. 17) was modified by homologous recombination in bacteria using a targeting vector containing 5' (AscI-SalI 460-bp) and 3' (SpeI-PacI 440-bp) homology regions, an iCreER ${ }^{\mathrm{T} 2}$ cassette (3.3 kb) (22), and the chloramphenicol resistance gene $\left(\mathrm{Cm}^{R}\right)$, which was flanked by $F R T$ sites and therefore could be removed by transient activation of Flp recombinase in bacteria (Figure 2A and ref. 23). Separation of Sox10iCreER ${ }^{\mathrm{T} 2}$ sequences from the vector and generation of transgenic animals were carried out as described previously (49).

To generate the $R 26 R^{F P 635}$ reporter strain, the coding sequences of the red fluorescent protein FP635 (31) was inserted into the pROSA26 targeting vector downstream of a loxP-flanked neomycin resistance cassette containing three transcriptional stop signals (18). This plasmid was subsequently linearized with $\mathrm{KpnI}$ and used for electroporation of R1 ES cells. ES cell clones with a correctly targeted $R 26 R$ allele were identified by Southern blotting and used to establish the $R 26 R^{F P 635}$ reporter mouse strain.

Timed matings for embryonic studies were generated by crossing doubletransgenic animals with Parkes (outbred) mice. Noon of the day of vaginal plug detection was considered to be E0.5.

4-OHT (Sigma-Aldrich) was dissolved in an ethanol/sunflower oil (1:9) mixture at $10 \mathrm{mg} / \mathrm{ml}$ and stored at $4{ }^{\circ} \mathrm{C}$ (maximum 2 weeks) or at $-20^{\circ} \mathrm{C}$ (for months). For detailed characterization of Cre activity, $0.2 \mathrm{mg} / \mathrm{g}$ of 
4-OHT was administered by intraperitoneal injection to pregnant Parkes females crossed with Sox $10:: i \mathrm{CreER} R^{T 2} ;$ R26ReYFP males 9.5 days post coitum, and the embryos were analyzed at E12.5. To analyze neurogenesis in postnatal and adult ENS, we injected Sox $10:: i C_{r e E R^{T 2}} ; R 26 R e Y F P$ or $h G F A P::$ $C r e E R^{T 2} ; R 26 R e Y F P$ animals intraperitoneally with $0.1-0.2 \mathrm{mg} / \mathrm{g}$ of 4-OHT for 2 consecutive days. Control mice were not injected or injected with an ethanol/sunflower oil (1:9) mixture.

Genotyping was carried out by PCR using the following primer pairs: Cre, 5'-ATCCGAAAAGAAAACGTTGA-3', 5'-ATCCAGGTTAC-

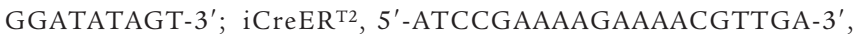
5'-ATCCAGGTTACGGATATAGT-3'; R26ReYFP, 5'-GCTCTGAGTT-

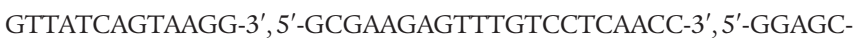
GGGAGAAATGGATAGT- $3^{\prime}$. All animal experiments were approved by the local National Institute for Medical Research ethical review panel in compliance with the United Kingdom Animal (Scientific Procedures) Act of 1986.

Cell culture. For short-term culture of dissociated embryonic intestine, whole gut from E16.5 embryos was dissected in L15 medium (Invitrogen), washed with $\mathrm{Ca}^{2+}$ - and $\mathrm{Mg}^{2+}$-free PBS (Invitrogen), and digested for 3 minutes with $1 \mathrm{mg} / \mathrm{ml}$ dispase/collagenase (Roche) at room temperature (RT). Dissociated tissue was washed with PBS and plated onto fibronectin-coated (20 $\mu \mathrm{g} / \mathrm{ml}$; Sigma-Aldrich) SONIC-SEAL slide wells (VWR) in OptiMEM (Life Technologies) supplemented with L-glutamine (1 mM, Life Technologies) and penicillin/streptomycin antibiotic mixture (Life Technologies). Cultures were maintained for up to 5 hours in an atmosphere of $5 \% \mathrm{CO}_{2}$.

To culture enteric crest-derived cells from adult mice, MS-MPs were isolated from the small intestine, washed in $0.1 \%$ penicillin/streptomycin in PBS, cut into small pieces, and then incubated in $1 \mathrm{mg} / \mathrm{ml}$ collagenase (Sigma-Aldrich), $100 \mu \mathrm{g} / \mathrm{ml}$ DNase I (Sigma-Aldrich) for 1 hour at $37^{\circ} \mathrm{C}$. After 2 washes in PBS, dissociated tissue was washed in NCSC culture medium, containing $15 \%$ chicken embryo extract, $20 \mathrm{ng} / \mathrm{ml} \mathrm{FGF} \mathrm{(R \& D}$ Systems), and $20 \mathrm{ng} / \mathrm{ml}$ EGF (Merck Biosciences) (21). Cells were plated onto fibronectin-coated ( $20 \mu \mathrm{g} / \mathrm{ml}$; Sigma-Aldrich) LabTek 8-well slide chambers (VWR) in NCSC medium and maintained in an atmosphere of $5 \% \mathrm{CO}_{2}$ for up to 6 months. Neuronal cultures were established by plating cells at medium density onto poly-D-lysin- and laminin-coated LabTek 8-well slide chambers in Neurobasal medium (Invitrogen) supplemented with 1\% N2 (Invitrogen) and 2\% B27 (Invitrogen).

Immunofluorescence and in situ hybridization. Immunofluorescence of dissociated gut cultures was carried out as reported previously (8). MS-MP preparations were fixed in $4 \%(\mathrm{w} / \mathrm{v}) \mathrm{PFA}$ in PBS for 30 minutes at RT, whereas embryos and guts were fixed for 2 hours at $4^{\circ} \mathrm{C}$. For sectioning, fixed tissue was cryoprotected overnight in $30 \%$ sucrose in PBS, incubated in PBS containing $15 \%$ sucrose and $7.5 \%$ gelatin, and then frozen in Tissue-Tek OCT on dry ice. Cryosections were cut at $12 \mu \mathrm{m}$. The antibodies used for immunofluorescence were: rabbit anti-BFABP (1:1,000, Millipore), rabbit anti-GFAP (1:300, Dako), mouse anti-HuC/D (1:500, Molecular Probes, Life Technologies), mouse anti-Ascl1 (1:500, a gift from F. Guillemot, NIMR, London, United Kingdom), rabbit anti-nNOS (1:200, Zymed, Invitrogen), rabbit anti-NPY (1:50, Biogenesis), rabbit anti-Phox $2 b$ (1:200, a gift from C. Goridis, Ecole Normale Supérieure, Paris, France), rabbit anti-SMA (1:250, Sigma-Aldrich), goat anti-Sox10 (1:200, Santa Cruz Biotechnology Inc.), rabbit anti-S100 $\beta$ (1:500, DAKO), mouse anti-synaptophysin (1:200, Dako). Rabbit anti-GFP (1:1,000, Molecular Probes, Life Technologies) and rat anti-GFP (1:1,000, Molecular Probes, Life Technologies) antibodies were used to study expression of the YFP reporter, and the two terms are used interchangeably. Primary antibodies were applied overnight at $4{ }^{\circ} \mathrm{C}$. Secondary antibodies were Alexa Fluor 488-, Alexa Fluor 568-, or Cy5-conjugated anti-rat, -rabbit, -mouse, or -goat (1:500, Molecular Probes, Life Technologies) and were applied for 2 hours at RT. All antibodies were diluted in PBS containing $0.1 \%$ Triton-X100 and $10 \%$ sheep serum or in PBS containing
$0.1 \%$ Triton $\mathrm{X}-100,1 \%$ bovine serum albumin, and $0.15 \%$ glycine. TOTO3 iodide (Molecular Probes, Life Technologies) was used to detect the cell nuclei. Following antibody treatment, samples were mounted in VECTASHIELD mounting medium containing DAPI (Vector Laboratories).

In situ hybridization histochemistry on cryosections was carried out as described previously (50). The following DNA fragments were used to generate digoxigenin-labeled riboprobes: rat Sox10, an EcoRI-BamHI 800-bp fragment (a gift from M. Wegner, Institut für Biochemie, Erlangen, Germany), and iCre, a 900-bp fragment spanning the entire iCre ORF (51).

$\left[\mathrm{Ca}^{2+}\right]_{i}-$ Fluo-4 imaging. Progenitor cells derived from MS-MP preparations isolated from Sox 10::iCreER ${ }^{T 2} ; R 26 R^{F P 635}$ or Sox $10:: i C r e E R^{T 2} ; R 26 R e Y F P$ animals were cultured for 7-10 days in NCSC medium and then seeded onto laminin/poly-D-lysine-coated glass coverslips in Neurobasal medium. After 5 days, patches of neurons could be identified by DIC microscopy. Cells were loaded with $5 \mu \mathrm{M}$ Fluo-4 AM (20 minutes), washed, and transferred to a cover glass chamber mounted on the microscope stage. The cells were constantly perfused with control or drug containing HEPES-buffered solution that was gravity fed $(1 \mathrm{ml} / \mathrm{min})$ via a multi-barrel perfusion system. The HEPES-buffered Krebs solution contained in mM: $148 \mathrm{NaCl}, 5$ $\mathrm{KCl}, 2 \mathrm{CaCl}_{2}, 1 \mathrm{MgCl}_{2}$, 10 glucose, 10 HEPES ( $\mathrm{pH}, 7.38$ ). The high- $\mathrm{K}^{+}$buffer used for neuron identification contained $75 \mathrm{mM} \mathrm{KCl}$, and $\mathrm{Na}^{+}$was reduced to $78 \mathrm{mM}$. For EFS (1 second, $20 \mathrm{~Hz}, 40 \mathrm{~mA}, 1$-ms pulses, WPI A385 stimulator) coverslips containing cultured cells were transferred to a recording chamber with two parallel Pt wires. All recordings were made at RT.

Fluorescence images were recorded using an inverted Zeiss Axiovert 200M microscope equipped with a TILL Poly V light source (TILL Photonics) and cooled CCD camera (PCO Sensicam-QE) using TillVisION (TILL Photonics). TurboFP635 (Evrogen) and YFP were excited, respectively, at $560 \mathrm{~nm}$ and $475 \mathrm{~nm}$. Fluorescence images were collected at 620/50 nm and 525/50 nm for FP635 and YFP, respectively. Changes in intracellular $\mathrm{Ca}^{2+}$ concentration $\left(\left[\mathrm{Ca}^{2+}\right]_{i}\right)$ reflected in Fluo-4 fluorescence intensity were recorded at 525/50 nm. All image analysis was performed with customwritten routines in IGOR Pro (Wavemetrics). Regions of interest (ROIs) were drawn over individual cells, fluorescence intensity was normalized to the basal fluorescence at the onset of the recording for each ROI, and peaks were analyzed. A peak was considered if the signal rose above a cutoff, which was set to the baseline plus 5 times the intrinsic noise level and the maximum $\left[\mathrm{Ca}^{2+}\right]_{\mathrm{i}}$ peak amplitude was determined. Color-coded images of responding cells (activity over time [AoT]) were generated by an automated routine that attributes, on a pixel by pixel basis, the maximum value of that pixel in a certain time window. The value was only assigned if a maximum significantly different from the starting value was observed; otherwise, the pixel in the AoT image was set to 0 . Thereby, all fluorescence information that was not changing in a given time window was filtered out. These images were falsely colored (green or blue) and overlaid with other AoT images in order to make differences in responses of neurons and glial cells visible.

BAC treatment. Sox 10::iCreER ${ }^{T 2} ; R 26 R e Y F P$ double transgenics, P84 or older, were injected intraperitoneally with $0.1-0.2 \mathrm{mg} / \mathrm{g}$ of $4-\mathrm{OHT}$ for 2 consecutive days. All animals were operated upon general isoflurane anesthesia. A laparotomy with a midline incision was performed, and a portion of the small intestine was exposed. Paper gauze soaked in $0.1 \%$ BAC (Sigma-Aldrich) in $0.9 \%$ Krebs solution was wrapped around $1 \mathrm{~cm}$ of the exteriorized intestine delineated with two serosal suture tags. The treatment was carried out for 5 minutes, after which the paper gauze was removed and the treated area and the peritoneum were thoroughly flushed with Krebs solution. Animals were sacrificed 3, 30, or 80 days after treatment. The treated segment of bowel and untreated segments orad and aborad to the treated area were harvested from each animal, and MSMPs were isolated for immunofluorescence. 
Image processing and cell counting. YFP expression in Sox10::Cre;R26ReYFP and Sox10::iCreER ${ }^{T 2} ; R 26 R e Y F P$ double-transgenic embryos and guts was analyzed using a Zeiss M2-Bio stereofluorescence microscope. Images were acquired with a Hamamatsu ORCA ER Digital Camera and Openlab software (Improvision). Immunostained cultures and MS-MP preparations were examined with a Zeiss epifluorescence Axioplan and Openlab software or with a Bio-Rad/Radiance 2100 confocal laser scanning microscope and LaserSharp software (Bio-Rad), using standard excitation and emission filters for visualizing DAPI, Alexa Fluor 488, Alexa Fluor 568, and Alexa Fluor 647. All images were processed with Adobe Photoshop CS 8.0 (Adobe Systems).

Statistics. Data are presented as mean \pm SEM, with the number of experiments shown in parentheses. Cell counting data were subjected to ANOVA or $\chi^{2}$ test for statistical significance. Differences were considered statistically significant when the $P$ value was less than 0.05 .

\section{Acknowledgments}

We thank François Guillemot (NIMR) for the anti-Ascl1 antibody and Christo Goridis (Ecole Normale Supérieure, Paris) for the anti-Phox2B antibody. We are very grateful to members of our laboratories, in particular Dipa Natarajan and Matthew Grist, for technical suggestions. We thank Biological Services (NIMR) and Mauro Tolaini for helping with the generation of transgenic mice. We thank Sean Morrison for useful comments on the manuscript and for sharing unpublished information with us. Work in V. Pachnis's laboratory is supported by the MRC. C. Laranjeira was supported by a predoctoral fellowship (SFRH/BD/22297/2005) from Fundação para a Ciência e a Technologia (FCT) and the MRC. K. Sandgren was supported by postdoctoral fellowships from the Wenner Gren Foundation, Wera Ekström Foundation, and the Swedish Society for Medical Research, with supporting grants from the H.R.H. Crown Princess Lovisas Foundation, the Professor Nanna Svartz Foundation, and Tore Nilsons Foundation. Work in P. Vanden Berghe's laboratory is supported by the Research Foundation-Flanders (FWO) (G.0501.10).

Received for publication March 28, 2011, and accepted in revised form June 27, 2011.

Address correspondence to: Vassilis Pachnis, Division of Molecular Neurobiology, MRC National Institute for Medical Research, The Ridgeway, Mill Hill, London NW7 1AA, United Kingdom. Phone: 0044.0.2088162113; Fax: 0044.0.2088162109; E-mail: vpachni@ nimr.nerc.ac.uk.

Katarina Sandgren's present address is: Neurogastroenterology, Department of Experimental Medical Science, Lund University, Lund, Sweden, and Department of Paediatric Surgery, Children's Hospital Lund, Skåne University Hospital, Malmö, Sweden.
1. Temple S, Alvarez-Buylla A. Stem cells in the adult mammalian central nervous system. Curr Opin Neurobiol. 1999;9(1):135-141.

2. Alvarez-Buylla A, Garcia-Verdugo JM, Tramontin AD. A unified hypothesis on the lineage of neural stem cells. Nat Rev Neurosci. 2001;2(4):287-293.

3. Dupin E, Calloni G, Real C, Goncalves-Trentin A, Le Douarin NM. Neural crest progenitors and stem cells. CR Biol. 2007;330(6-7):521-529.

4. Pardal R, Ortega-Saenz P, Duran R, Lopez-Barneo J. Glia-like stem cells sustain physiologic neurogenesis in the adult mammalian carotid body. Cell. 2007;131(2):364-377.

5. Kunze WA, Furness JB. The enteric nervous system and regulation of intestinal motility. Annu Rev Physiol. 1999;61:117-142.

6. Laranjeira C, Pachnis V. Enteric nervous system development: recent progress and future challenges. Auton Neurosci. 2009;151(1):61-69.

7. Paratore C, Eichenberger C, Suter U, Sommer L. Sox10 haploinsufficiency affects maintenance of progenitor cells in a mouse model of Hirschsprung disease. Hum Mol Genet. 2002;11(24):3075-3085.

8. Bondurand N, Natarajan D, Thapar N, Atkins C, Pachnis $\mathrm{V}$. Neuron and glia generating progenitors of the mammalian enteric nervous system isolated from foetal and postnatal gut cultures. Development. 2003;130(25):6387-6400.

9. Anderson RB, Stewart AL, Young HM. Phenotypes of neural-crest-derived cells in vagal and sacral pathways. Cell Tissue Res. 2006;323(1):11-25.

10. Mollaaghababa R, Pavan WJ. The importance of having your SOX on: role of SOX10 in the development of neural crest-derived melanocytes and glia. Oncogene. 2003;22(20):3024-3034.

11. Pham TD, Gershon MD, Rothman TP. Time of origin of neurons in the murine enteric nervous system: sequence in relation to phenotype.J Comp Neurol. 1991;314(4):789-798.

12. Liu MT, Kuan YH, Wang J, Hen R, Gershon MD. 5 -HT4 receptor-mediated neuroprotection and neurogenesis in the enteric nervous system of adult mice. J Neurosci. 2009;29(31):9683-9699.

13. Kruger GM, Mosher JT, Bixby S, Joseph N, Iwashita
T, Morrison SJ. Neural crest stem cells persist in the adult gut but undergo changes in self-renewal, neuronal subtype potential, and factor responsiveness. Neuron. 2002;35(4):657-669.

14. Suarez-Rodriguez R, Belkind-Gerson J. Cultured nestin-positive cells from postnatal mouse small bowel differentiate ex vivo into neurons, glia, and smooth muscle. Stem Cells. 2004;22(7):1373-1385.

15. Filogamo G, Cracco C. Models of neuronal plasticity and repair in the enteric nervous system: a review. Ital J Anat Embryol. 1995;100(suppl 1):185-195.

16. Geboes K, Collins S. Structural abnormalities of the nervous system in Crohn's disease and ulcerative colitis. Neurogastroenterol Motil. 1998;10(3):189-202.

17. Matsuoka T, et al. Neural crest origins of the neck and shoulder. Nature. 2005;436(7049):347-355.

18 . Srinivas $S$, et al. Cre reporter strains produced by targeted insertion of EYFP and ECFP into the ROSA26 locus. BMC Dev Biol. 2001;1:4.

19. Young HM, Bergner AJ, Muller T. Acquisition of neuronal and glial markers by neural crestderived cells in the mouse intestine. J Comp Neurol. 2003;456(1):1-11

20. Wakamatsu Y, Weston JA. Sequential expression and role of Hu RNA-binding proteins during neurogenesis. Development. 1997;124(17):3449-3460.

21. Morrison SJ, White PM, Zock C, Anderson DJ. Prospective identification, isolation by flow cytometry, and in vivo self-renewal of multipotent mammalian neural crest stem cells. Cell. 1999;96(5):737-749.

22. Claxton S, Kostourou V, Jadeja S, Chambon P, Hodivala-Dilke K, Fruttiger M. Efficient, inducible Cre-recombinase activation in vascular endothelium. Genesis. 2008;46(2):74-80.

23. Lee EC, et al. A highly efficient Escherichia colibased chromosome engineering system adapted for recombinogenic targeting and subcloning of BAC DNA. Genomics. 2001;73(1):56-65.

24. Stemple DL, Anderson DJ. Isolation of a stem cell for neurons and glia from the mammalian neural crest. Cell. 1992;71(6):973-985.

25. Young HM, Hearn CJ, Ciampoli D, Southwell BR, Brunet JF, Newgreen DF. A single rostrocaudal colonization of the rodent intestine by enteric neuron precursors is revealed by the expression of Phox $2 \mathrm{~b}$, Ret, and $\mathrm{p} 75$ and by explants grown under the kidney capsule or in organ culture. Dev Biol. 1998;202(1):67-84

26. Heanue TA, Pachnis V. Prospective identification and isolation of enteric nervous system progenitors using SOX2. Stem Cells. 2011;29(1):128-140.

27. Blaugrund E, et al. Distinct subpopulations of enteric neuronal progenitors defined by time of development, sympathoadrenal lineage markers and Mash-1-dependence. Development. 1996; 122(1):309-320.

28. Hao MM, Young HM. Development of enteric neuron diversity. J Cell Mol Med. 2009;13(7):1193-1210.

29. Ganat YM, et al. Early postnatal astroglial cells produce multilineage precursors and neural stem cells in vivo. J Neurosci. 2006;26(33):8609-8621.

30. Vanden Berghe P, Missiaen L, Janssens J, Tack $\mathrm{J}$. Calcium signalling and removal mechanisms in myenteric neurones. Neurogastroenterol Motil. 2002;14(1):63-73.

31. Shcherbo D, et al. Far-red fluorescent tags for protein imaging in living tissues. Biochem $\mathrm{J}$. 2009;418(3):567-574.

32. Gomes P, et al. ATP-dependent paracrine communication between enteric neurons and glia in a primary cell culture derived from embryonic mice. Neurogastroenterol Motil. 2009;21(8):870-e862.

33. Vanden Berghe P, Klingauf J. Spatial organization and dynamic properties of neurotransmitter release sites in the enteric nervous system. NeuroScience. 2007;145(1):88-99.

34. Vanden Berghe P, Tack J, Boesmans W. Highlighting synaptic communication in the enteric nervous system. Gastroenterology. 2008;135(1):20-23.

35. Fox DA, Epstein ML, Bass P. Surfactants selectively ablate enteric neurons of the rat jejunum. JPharmacol Exp Ther. 1983;227(2):538-544.

36. Hanani $M$, et al. Regeneration of myenteric plexus in the mouse colon after experimental denervation with benzalkonium chloride. J Comp Neurol. 2003;462(3):315-327.

37. Ramalho FS, Santos GC, Ramalho LN, Kajiwara JK, Zucoloto S. Myenteric neuron number after acute 
and chronic denervation of the proximal jejunum induced by benzalkonium chloride. Neurosci Lett. 1993;163(1):74-76.

38. Bixby S, Kruger GM, Mosher JT, Joseph NM, Morrison SJ. Cell-intrinsic differences between stem cells from different regions of the peripheral nervous system regulate the generation of neural diversity. Neuron. 2002;35(4):643-656.

39. Hoff S, et al. Quantitative assessment of glial cells in the human and guinea pig enteric nervous system with an anti-Sox8/9/10 antibody. J Comp Neurol. 2008;509(4):356-371.

40. Temple S. The development of neural stem cells. Nature. 2001;414(6859):112-117.

41. Joseph NM, He S, Quintana E, Kim Y-G, Núñez G, Morrison SJ. Enteric glia are multipotent in culture but primarily form glia in the adult rodent gut. J Clin Invest. doi: 10.1172/JCI58186.

42. Fellin T. Communication between neurons and astro- cytes: relevance to the modulation of synaptic and network activity. J Neurochem. 2009;108(3):533-544.

43. Alvarez-Buylla A, Seri B, Doetsch F. Identification of neural stem cells in the adult vertebrate brain. Brain Res Bull. 2002;57(6):751-758.

44. Ooto $S$, et al. Potential for neural regeneration after neurotoxic injury in the adult mammalian retina. Proc Natl Acad Sci U S A. 2004;101(37):13654-13659.

45. Heinrich C, et al. Directing astroglia from the cerebral cortex into subtype specific functional neurons. PLoS Biol. 2010;8(5):e1000373.

46. Wood JD. Neuropathy in the brain-in-the-gut. Eur J Gastroenterol Hepatol. 2000;12(6):597-600.

47. Steinhoff MM, Kodner IJ, DeSchryver-Kecskemeti $\mathrm{K}$. Axonal degeneration/necrosis: a possible ultrastructural marker for Crohn's disease. Mod Pathol. 1988;1(3):182-187.

48. Indra AK, et al. Temporally-controlled site-specific mutagenesis in the basal layer of the epidermis: com- parison of the recombinase activity of the tamoxifeninducible Cre-ER(T) and Cre-ER(T2) recombinases. Nucleic Acids Res. 1999;27(22):4324-4327.

49. Fogarty M, Grist M, Gelman D, Marin O, Pachnis $\mathrm{V}$, Kessaris N. Spatial genetic patterning of the embryonic neuroepithelium generates GABAergic interneuron diversity in the adult cortex.J Neurosci. 2007;27(41):10935-10946.

50. Schaeren-Wiemers N, Gerfin-Moser A. A single protocol to detect transcripts of various types and expression levels in neural tissue and cultured cells: in situ hybridization using digoxigenin-labelled cRNA probes. Histochemistry. 1993; 100(6):431-440.

51. Kessaris N, Fogarty M, Iannarelli P, Grist M, Wegner M, Richardson WD. Competing waves of oligodendrocytes in the forebrain and postnatal elimination of an embryonic lineage. Nat Neurosci. 2006;9(2):173-179 